\title{
POLÍTICAS PÚBLICAS AMBIENTAIS: SISTEMA DE COLETA SELETIVA DO MUNICÍPIO DE PRESIDENTE EPITÁCIO-SP
}

\author{
Leila Maria Couto Esturaro Bizarro'
}

Alba Regina de Azevedo Arana ${ }^{2}$

\section{Edilene Mayumi Murashita Takenaka ${ }^{3}$}

RESUMO: O excesso de consumo, decorrente do aumento populacional, gera grande volume de resíduos sólidos descartados, ocasionando impactos ao meio ambiente. Frente a esta problemática, as cidades brasileiras buscam implantar maneiras de gerenciamento de resíduos sólidos como uma solução de minimização desta questão, como no caso da cidade de Presidente Epitácio - SP, objeto deste estudo, que até meados da década de 90 enfrentava problemas com a destinação inadequada de seus resíduos sólidos. Com a finalidade de reduzir os impactos provocados pela disposição final inadequada no município, encontrou-se como alternativa a implantação do sistema de coleta seletiva e reciclagem dos seus resíduos sólidos através da criação da ARPE (Associação de Recicladores de Presidente Epitácio) para realização deste serviço. Este estudo desenvolveu-se com fundamentação teórica, através de levantamento bibliográfico, e pesquisa de campo junto a Prefeitura Municipal da Estância Turística de Presidente Epitácio - SP e a Associação, com o objetivo de realizar uma análise do sistema atual do

\footnotetext{
${ }^{1}$ Mestranda em Meio Ambiente e Desenvolvimento Regional, Universidade do Oeste Paulista - UNOESTE. leila@unoeste.br

${ }^{2}$ Doutora em Geografia pela Universidade de São Paulo - USP. Docente do Mestrado em Meio Ambiente e Desenvolvimento Regional da Universidade do Oeste Paulista UNOESTE - alba@unoeste.br

${ }^{3}$ Doutora em Geografia pela FCT/UNESP. Docente do Mestrado em Meio Ambiente e Desenvolvimento Regional da Universidade do Oeste Paulista - UNOESTE - edilene@unoeste.br
} 
serviço de coleta seletiva realizado pela ARPE. Conclui-se que, mesmo com um grande programa de educação ambiental desenvolvido no início da implantação do sistema, o processo de formação e informação junto à comunidade epitaciana sobre os aspectos ambientais da coleta seletiva deve ser contínuo, pois somente com a sensibilização da população com relação às questões ambientais e sociais haverá aumento da quantidade de resíduos sólidos recicláveis coletados e, consequentemente, aumento da renda dos associados que trabalham na ARPE e da vida útil do aterro controlado existente no município.

Palavras-chave: Resíduos sólidos. Coleta seletiva. Reciclagem. Associação.

\section{INTRODUÇÃO}

O Homem é um inquilino do Planeta Terra e a ocupação dos espaços terrestres no transcorrer dos séculos foi se adaptando as circunstâncias temporais, até os dias atuais, quando já ultrapassamos os 07 bilhões de habitantes.

Para a sobrevivência desse grande contingente de seres vivos gera-se a necessidade diária de produção de alimentos, disponibilidade de água potável, empregos, construção de habitações, entre outras questões básicas para a permanência da vida de qualquer ser humano. Outro grande desafio é adequar à gestão dos rejeitos gerados por todos, pois além dos rejeitos domésticos, há a geração dos resíduos industriais advindos da expansão da atividade industrial, que aumenta dia a dia devido ao crescimento populacional.

O aumento do consumo de bens cada dia mais descartáveis são decorrentes de fatores como o aumento populacional, melhoria da qualidade de vida e, de forma geral, maior poder aquisitivo advindo de uma economia estável. O excesso de consumo gera grande volume de resíduos sólidos descartados, ocasionando impactos ao meio ambiente.

Frente a esta problemática, as cidades brasileiras buscam implantar maneiras de gerenciamento de resíduos sólidos como uma solução de minimização desta questão, como no caso da cidade de Presidente Epitácio - SP, objeto deste estudo, que até 
meados da década de 90 enfrentava problemas com a destinação inadequada de seus resíduos sólidos.

Com a finalidade de reduzir os impactos provocados pela disposição final inadequada no município, encontrou-se como alternativa a implantação do sistema de coleta seletiva e reciclagem dos seus resíduos sólidos através da criação da ARPE (Associação de Recicladores de Presidente Epitácio) para realização deste serviço.

O trabalho se justifica ante a necessidade de se conhecer medidas socioambientais que prosperam diante dos problemas antes existentes, devido à ausência de um programa de coleta seletiva no município pesquisado.

Este estudo desenvolveu-se com fundamentação teórica, através de levantamento bibliográfico, e pesquisa de campo junto à Prefeitura Municipal da Estância Turística de Presidente Epitácio, estado de São Paulo e à Associação de Recicladores, com o objetivo de realizar uma análise do sistema atual do serviço de coleta seletiva realizado pela ARPE.

\section{RECURSOS NATURAIS E CRESCIMENTO POPULACIONAL}

A possibilidade da vida em sua plenitude depende de recursos naturais existentes e da disponibilidade de solo, da água e ar. Portanto, o homem depende do meio ambiente e só pode viver em ambientes com determinadas características e com certa variedade desses recursos disponíveis (BOTKIN; KELLER, 2011).

Ocorre, porém que a utilização dos recursos naturais pelo homem nem sempre ocorreu de forma a considerar a capacidade de recuperação dos mesmos e, só recentemente, ele passou a preocupar-se com os problemas ambientais, levando-o a procurar compreender seus fenômenos naturais e a entender que deve agir como parte integrante desse sistema natural, visto que o homem e a natureza estão intimamente interligados e as mudanças em um deles provocam inevitavelmente alterações no outro.

Ao longo da história, o ser humano vem modificando os ecossistemas desconsiderando que os recursos naturais são finitos. Em muitas partes do Planeta encontram-se situações de escassez e degradações, tornando-se difícil a sobrevivência 
dos seres vivos (MOTTA, 2010). "O problema é que a Terra não cresceu em tamanho e em abundância de seus recursos também não aumentou (BOTKIN e KELLER, p.3, 2011).

Segundo o (PNUMA) Programa das Nações Unidas para o Meio Ambiente (2012) a pressão sobre os recursos terrestres tem aumentado nos últimos anos e o crescimento econômico tem acontecido à custa dos recursos naturais e dos ecossistemas.

Os problemas ambientais agravaram-se e observa-se que a situação atual tem a sua origem no modelo de desenvolvimento econômico surgido com a Revolução Industrial, no século XVIII, quando a população ganhou com a redução das taxas de mortalidade e com o crescimento da expectativa de vida, vivendo-se a partir de então progressivamente mais e melhor. "Nunca na história vivemos por tanto tempo - nem tão bem" (VASSALO, 2011, p.10). "Entre 1800 e 2010 a população mundial cresceu, aproximadamente, sete vezes (de 1 bilhão para 7 bilhões) e a economia (PIB) aumentou cerca de 50 vezes. Mas o crescimento da riqueza se deu à custa da pauperização do planeta ( ALVES, 2010, p. 24).

Em nenhum momento da história humana verificou-se de forma tão nítida a forma imprudente que o homem vem tratando os sistemas que asseguram a vida na Terra (DIAS, 2006). Portanto, as mudanças de comportamento em relação à geração dos resíduos sólidos e, consequentemente, a sua gestão tem se tornado, além de uma determinação legal, uma necessidade, visto que quando jogamos um objeto "fora", de forma ilusória achamos que estamos descartando para longe ou bem distante dos nossos olhos, porém o "fora" está muito mais perto do que imaginamos, posto que no Planeta Terra não existe lugar ou espaço que não esteja integrado a tudo e a todos.

\subsection{Resíduos sólidos}

Para a correta adequação dessa gestão, é imprescindível diferenciar as terminologias "lixo" e "resíduos sólidos", que aparentemente têm o mesmo significado.

Para Bidone (1999), os materiais descartados não-reutilizáveis eram chamados, até um passado recente, de lixo. Para o autor, "a palavra lixo origina-se do latim lix, que significa cinzas ou lixívia. Atualmente, o lixo é identificado, como basura nos países de 
língua espanhola, e refuse, garbage, solid waste nos países de língua inglesa".

Segundo Dias (2004, p. 40), "A palavra lixo não deve ser mais utilizada. Ela expressava "o que não presta, não serve para nada". A cultura do "lixo" deve desaparecer para dar lugar à cultura dos resíduos sólidos (matéria-prima a ser reaproveitada)"

Para Braga (2005, p. 147) "os resíduos sólidos de uma área urbana são constituídos por aquilo que vulgarmente se denomina 'lixo' e até por resíduos especiais, quase sempre mais problemáticos e perigosos, provenientes de domicílios, indústrias e hospitais".

Costa (2004) diz que não há um lixo único. Há vários tipos de lixo, inclusive um material limpo, reciclável, que pode ter várias destinações, inclusive reutilizá-lo como matéria-prima para outros produtos.

A definição de resíduos sólidos segundo a ABNT (Associação Brasileira de Normas Técnicas), através da NBR 10004: 2004 é:

\begin{abstract}
Resíduos nos estados sólidos e semissólido, que resultam de atividades de origem industrial, doméstica, hospitalar, comercial, agrícola, de serviços e de varrição. Ficam incluídos nesta definição lodos provenientes de sistemas de tratamento de água, aqueles gerados em equipamentos e instalações de controle de poluição, bem como determinados líquidos cujas particularidades tornem inviável o seu lançamento na rede pública de esgotos ou corpos d'água, ou exijam para isso soluções técnicas e economicamente inviáveis em face á melhor tecnologia disponível.
\end{abstract}

\title{
2.2 Política Nacional de Resíduos Sólidos
}

A Lei n. -12.305 , de 02 de agosto e 2010, que institui a Política Nacional de Resíduos Sólidos, veio de encontro às necessidades da sociedade em estabelecer conceitos, instrumentos, princípios, instrumentos, prazos, diretrizes e planos de gerenciamento dos resíduos sólidos em todos os níveis da gestão pública, ou seja, nas esferas municipal, estadual e federal estabelecendo a responsabilidade compartilhada pelo ciclo de vida útil dos produtos, conceito até então desconhecido em todos os âmbitos.

Dentro dessa nova legislação objetiva-se implementar a política do lixo mínimo em todos os segmentos da sociedade, ou seja, diferentemente do conceito de lixo, que é 
o resto descartado ou inservível dentro do ciclo de vida útil do produto, os resíduos sólidos apresentam critérios técnicos para o seu aproveitamento, conforme extrai-se do

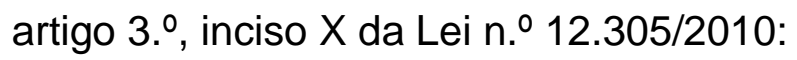

\begin{abstract}
X - gerenciamento de resíduos sólidos: conjunto de ações exercidas, direta ou indiretamente, nas etapas de coleta, transporte, transbordo, tratamento e destinação final ambientalmente adequada dos resíduos sólidos e disposição final ambientalmente adequada dos rejeitos, de acordo com plano municipal de gestão integrada de resíduos sólidos ou com plano de gerenciamento de resíduos sólidos, exigidos na forma desta Lei;
\end{abstract}

Observa-se assim, que a terminologia "lixo" passou a ser não mais utilizada para indicar aqueles produtos que descartamos, pois a lei exige o seu gerenciamento integrado, onde cada um de nós faz parte desse ciclo de responsabilidade, inserindo os produtos que compramos, consumimos e, posteriormente, jogamos fora, num contexto ambientalmente adequado.

A regulamentação dessa lei deu-se pelo Decreto Federal n. ${ }^{\circ} 7.404 / 2010$, que por meio da instituição de normas pretende viabilizar a aplicabilidade de seus instrumentos, mas efetivamente terá resultados quando houver uma participação massiva da sociedade através do instrumento de transformação que é a educação ambiental, para a construção de uma sociedade sustentável.

Só assim será possível realizar um descarte adequado de nossos resíduos sólidos gerados cotidianamente para um gerenciamento adequado, objetivando aproveitar a matéria-prima na transformação de outros subprodutos através de técnicas da logística reversa, poupando recursos ambientais in natura e encaminhando para o descarte definitivo em forma de lixo, o mínimo possível.

\title{
2.3 Geração de resíduos sólidos
}

De acordo com Eleutério (2010, p. 25) "o Compromisso Empresarial para a Reciclagem (CEMPRE) indica que o Brasil gera diariamente cerca de 150 mil toneladas de lixo urbano. Desse montante, $76 \%$ são depositados em lixões a céu aberto. Ou seja, a cada quatro sacolas de lixo, três são destinados de forma incorreta" 
Em tempo, ele dispõe que o país acordou para a questão e com o Plano Nacional de Resíduos Sólidos, Lei n.ำ 12.305/2010, que prevê que a partir de 2014 seja o prazo final dessa forma incorreta de descarte, quando será obrigatória a todos os municípios brasileiros a implementação de uma gestão ambientalmente correta para seus resíduos.

Eleutério $(2010$, p.25) relata que "nas grandes cidades brasileiras, cada cidadão produz, em média, um quilo de resíduo por dia."

Ante essa problemática atual, observa-se a necessidade de uma nova postura ambiental que não deve ser apenas do poder público, mas sim de uma conduta diuturna de todos nós, consumidores e gerados de resíduos, assim como de todos os atores envolvidos na gestão integrada, seja o fabricante, distribuidor, comerciante e demais espaços públicos e privados onde haja produção de resíduos.

\subsection{Coleta seletiva}

De acordo com Miranda (1995), entende-se por coleta seletiva o procedimento de separação na origem, do lixo a ser coletado, em orgânico e inorgânico.

Segundo Jardim (1995), a coleta seletiva tem embasamento na realização da separação na própria fonte geradora dos materiais recicláveis e que podem ser reutilizados mediante acondicionamento.

Para Bartolomeu e Caixeta-Filho (2011) o sistema de coleta seletiva consiste no potencial de reciclagem dos resíduos como papel, papelão, plástico e metal (materiais ferrosos e não ferrosos).

O principal ponto positivo deste gerenciamento é a redução da quantidade de resíduos a serem dispostos em aterro e um dos fatores importantes para sua eficiência é a participação da comunidade neste processo, pois é através da população que se realiza o acondicionamento e a segregação dos resíduos na fonte ao separarem os materiais recicláveis dos não recicláveis, também chamados de lixo úmido ou simplesmente lixo, que são compostos por matéria orgânica.

Para Bartolomeu e Caixeta-Filho (2011, p. 25): 


\begin{abstract}
O sistema de coleta seletiva se pressupõe que os resíduos sejam triados pelos geradores facilitando o manejo, separação e comercialização pelas cooperativas de reciclagem. Os materiais recicláveis compõem cerca de $40 \%$ dos resíduos sólidos domiciliares, e seu aproveitamento, além de poupar energia, contribui para redução na quantidade e do volume de resíduos que são dispostos em aterros, ampliando a vida útil destes locais de destinação.
\end{abstract}

Desta forma, a coleta seletiva exerce um papel importante para a preservação do meio ambiente, pois por meio dela recuperam-se matérias primas que seriam extraídas da natureza e a educação ambiental passa a ser o instrumento a capacitar as pessoas de como modificar suas atitudes em relação ao meio ambiente, de forma contínua e permanente.

\title{
2.5 Educação ambiental
}

Para Dias (2004), o processo de Educação Ambiental objetiva que as pessoas adquiram respeito pelo meio ambiente e almejem a busca pelo conhecimento, valores e experiências que os tornem capazes de solucionar problemas ambientais no presente e no futuro.

A educação ambiental segundo a Lei n.ำ 9.795/99 é:

Art. $1^{\circ}$ Entendem-se por educação ambiental os processos por meio dos quais o indivíduo e a coletividade constroem valores sociais, conhecimentos, habilidades, atitudes e competências voltadas para a conservação do meio ambiente, bem de uso comum do povo, essencial à sadia qualidade de vida e sua sustentabilidade.

Art. $2^{\circ} \mathrm{A}$ educação ambiental é um componente essencial e permanente da educação nacional, devendo estar presente, de forma articulada, em todos os níveis e modalidades do processo educativo, em caráter formal e não-formal.

Dias (2006) afirma que a Educação Ambiental é um conjunto de atividades que objetiva formar e informar as pessoas sobre a complexidade da temática ambiental, propondo ações que envolvam mudanças de hábitos e propicie reflexões sobre as relações do ser humano com o ambiente.

Para Milaré (2000, p.226):

A educação Ambiental deve ser considerada como uma atividade-fim, porquanto se destina a despertar e formar a consciência ecológica para o exercício da 
cidadania. Não é panacéia para resolver todos os males; sem dúvida, porém é um instrumental valioso na geração de atitudes, hábitos e comportamentos que concorrem para garantira qualidade do ambiente como patrimônio da coletividade.

Desse modo a educação ambiental tem como um dos seus objetivos principais a mudança de valores, hábitos, condutas na relação do homem com o meio ambiente, através de atividades simples do cotidiano como a realização da coleta seletiva, a reciclagem, a conservação dos recursos naturais, sendo uma ferramenta imprescindível para a minimização dos problemas da disposição final dos resíduos sólidos ou do lixo.

A educação ambiental é o instrumento que possibilita a mudança de hábitos de consumo, possibilitando a redução da quantidade de resíduos produzidos pela população, assim como pela disposição final adequada destes em prol da proteção dos recursos naturais e da melhoria da qualidade de vida de todos.

\section{PROBLEMÁTICA AMBIENTAL EM PRESIDENTE EPITÁCIO-SP}

Segundo Dal Más (2003), em 1999 o município de Presidente Epitácio - SP enfrentava uma problemática envolvendo o acondicionamento do lixo, que era realizado a céu aberto, às margens da Via Marginal Juliano Ferraz Lima, às vistas do Rio Paraná, e era denominado lixão. Não havia, na época, uma política pública estruturada para tratar do mesmo como requer um ambiente equilibrado. Em uma reunião entre todos os municípios do Pontal do Paranapanema foi apontada esta situação caótica, onde, além da responsabilização sobre a mudança desta cultura, houve a notificação e a determinação de um período para implantação de um sistema que estivesse em conformidade com as normas ambientais.

Através desta notificação houve uma manifestação de caráter positivo por parte do Poder Público Municipal, que se empenhou em realizar pesquisas para a implantação do aterro controlado em substituição ao lixão a céu aberto, que produzia além maus odores e propiciava a proliferação de vetores.

O lixão foi desativado no mês de junho do corrente ano, resolvendo assim a questão ambiental. Todavia, instalou-se um problema social no município, uma vez que dezessete famílias tiravam seu sustento por intermédio da catação dos materiais 
recicláveis existentes naquele local, informalmente e sem medidas de prevenção contra acidentes. Havia famílias que dependiam deste trabalho há mais de vinte anos, sendo comum até mesmo a presença constante de crianças que, além de catar os materiais, também se alimentavam dos alimentos ali depositados.

Ainda segundo o mesmo autor, o aterro controlado foi implantado em setembro de 1999, vindo do acordo firmado no TAC (Termo de Ajustamento de Conduta). Este aterro foi estruturado em formas de valas e exigiu normas de segurança devido ao trabalho contínuo de máquinas e caminhões. A área ficou restrita aos funcionários credenciados ao local, sendo proibida a entrada de catadores informais, em função dos riscos inerentes à operacionalização dos trabalhos.

Acarretaram-se, assim, problemas sociais relacionados ao desemprego e a Secretaria de Serviço Social Municipal empenhou-se em incluí-los no mercado de trabalho sem obter sucesso, devido à falta de capacitação por parte dos mesmos ou pelo preconceito de alguns empresários que os rejeitavam e recusavam-se a contratá-los.

A Prefeitura Municipal da Estância Turística de Presidente Epitácio-SP tomou como objetivo a realização de estudos e pesquisas para implantação de um sistema de coleta seletiva de lixo domiciliar que viria a contribuir para a fonte de renda dos catadores através de trabalho formal e da melhoria da qualidade de vida dos munícipes. Por intermédio de convênio com o Comitê da Bacia Hidrográfica do Pontal do Paranapanema (CBH-PP) foi construído na área pública do aterro sanitário um barracão de $200 \mathrm{~m}^{2} \mathrm{e}$ comprada uma prensa para materiais recicláveis para instalação da ARPE.

\subsection{Implantação da coleta seletiva em Presidente Epitácio - SP}

Inicialmente, o sistema adotado para implementar a coleta seletiva no município, foi dividir o perímetro urbano do município em cinco setores, organizando a distribuição da coleta seletiva pelo grupo de trabalho da ARPE, sendo que cada setor é realizado em um dia da semana, de segunda a sexta-feira, quando os associados passam de porta em porta na área delimitada.

Os trabalhos foram iniciados em 26 de maio do ano de 2003 e, na primeira 
semana, os membros da ARPE visitaram todas as residências do município, entregando um saco plástico de cor verde juntamente com uma cartilha explicativa, informando as pessoas e pedindo para que realizassem a separação dos materiais recicláveis.

$\mathrm{Na}$ segunda semana foi realizada a primeira coleta dos materiais que foram separados pela população. Os membros da ARPE chamavam o morador ao portão e o morador entregava o saco com os recicláveis e recebia de volta um saco verde novo para que desse continuidade à separação do lixo em sua residência. A troca do saco cheio por um vazio tinha como objetivo o contato dos moradores com os membros da ARPE, que agradeciam pela colaboração e orientavam para que não deixassem de realizar a separação.

$\mathrm{Na}$ terceira semana, os membros foram divididos em duas equipes: uma equipe para realizar o serviço de coleta seletiva no município porta a porta e uma equipe para trabalhar na triagem dos materiais recicláveis no barracão.

Para a realização do sistema de coleta seletiva foi estabelecida uma parceria entre a Prefeitura Municipal e a ARPE, onde a Prefeitura assumiu a responsabilidade de fornecer o caminhão com motorista e combustível para o transporte dos materiais recicláveis provenientes da coleta seletiva, os sacos verdes e o barracão de triagem.

No barracão de triagem, as equipes se dividem em dois turnos diários, das 8:00h até as 15:00h e das 15:00h às 22:00h. O processo de triagem compreende a separação dos materiais conforme seu tipo, posterior acondicionamento e prensagem, para facilitar o armazenamento, agilizando o manuseio e o transporte dos fardos e sua comercialização. Os materiais que não podem ser reaproveitados na comercialização são considerados rejeitos e são levados para o aterro controlado.

Os principais materiais triados pela Associação são: papéis, papelão, vidro, alumínio, metais e plásticos, de diversos tipos. Os fardos dos resíduos recicláveis são armazenados e empilhados em um local coberto, para evitar danos aos mesmos, até alcançarem a quantidade necessária para serem revendidos. Atualmente, a ARPE comercializa, em média, 58 toneladas/mês de materiais recicláveis.

\section{CONSIDERAÇÕES FINAIS}


Em análise das informações oriundas de levantamento bibliográfico e trabalhos de campo, conclui-se que o sistema de coleta seletiva contribui com a redução de impactos ambientais no município de Presidente Epitácio - SP diminuindo o volume de resíduos lançados de maneira inadequada; aumentando da vida útil do aterro controlado; minimizando a extração de matéria-prima, através da reintegração do material reciclado como matéria-prima secundária ao ciclo produtivo, mostrando-se, assim, como uma forma eficiente de gerenciamento.

Além da redução dos impactos ambientais relacionados, outra importante contribuição é a geração de renda através da Associação, que realiza o serviço de coleta seletiva no município, e que mesmo com os problemas existentes em seu funcionamento, devido à deficiência da educação ambiental da comunidade analisada, consegue suprir as necessidades ambientais e sociais do município.

Pode-se concluir que, mesmo com um grande programa de educação ambiental desenvolvido no início da implantação do sistema, o processo de formação e informação junto à comunidade epitaciana sobre os aspectos ambientais da coleta seletiva deve ser contínuo, pois somente com a sensibilização da população com relação às questões ambientais e sociais haverá aumento da quantidade de resíduos sólidos recicláveis coletados e, consequentemente, a redução dos impactos ambientais, aumento da geração de renda dos associados que trabalham na ARPE e da vida útil do aterro controlado existente no município.

Observa-se por fim, que a responsabilidade ambiental pela qualidade e eficiência do serviço prestado pela ARPE no município de Presidente Epitácio - SP, não é só de competência do Poder Público Municipal, mas sim de cada munícipe ao exercer plenamente a sua cidadania ao realizar a sua parte dentro desse ecossistema comum denominado de Planeta Terra.

\section{REFERÊNCIAS}

ABNT - Associação Brasileira de Normas Técnicas. Resíduos Sólidos - Classificação 
NBR10002:2004, 2êed., 2004 .

ALVES, J. E. D. A Terra no Limite. Revista Veja. Especial Sustentabilidade, Editora Abril, Edição Especial. Ano 43 (Veja 2196). Dezembro, 2010.

BARTOLOMEU, D. B.; CAIXEITA-FILHO, J. V. Logística ambiental de resíduos sólidos. São Paulo: Atlas, 2011.

BIDONE, F. R. A. Conceitos Básicos de Resíduos Sólidos. São Carlos: EESC/USP, 1999.

BOTKIN, D. B.; KELLER, E.A. Ciência Ambiental: Terra, um planeta vivo; tradução Francisco Vecchia; Luiz Cláudio de Queiroz Faria - revisão técnica Marcos José de Oliveira. Rio de Janeiro: LTC, 2010.

BRAGA, B. Introdução à Engenharia Ambiental. 2ª ed., Person Prentince Hall, 2005.

BRASIL. Lei n.o 9.795, de 27 de abril de 1.999. Dispõe sobre a educação ambiental, institui a Política Nacional de Educação Ambiental e dá outras providências. Disponível em http://www4.planalto.gov.br/legislacao/legislacao-1/leis-ordinarias/legislacao-1/leisordinarias/1999\#content. Acesso em 06 Set. 2013.

BRASIL. Lei no 12.305, de 02 de agosto de 2010. Institui a Política Nacional de Resíduos Sólidos; altera a Lei no 9.605, de 12 de fevereiro de 1998; e dá outras providências. Disponível em: <http://www.planalto.gov.br/ccivil_03/_Ato2007-2010/2010/Lei/L12305.htm / >. Acesso em: 01 set. 2013.

COSTA, S. S. Lixo Mínimo: uma proposta ecológica para hotelaria. Rio de Janeiro: Senac, 2004.

DAL MÁS, A. D. Lixo sobre a ótica do direito. 2003. Trabalho de Conclusão de Curso (Bacharel em Direito) - Faculdade de Ciências Jurídicas, Administrativas Contábeis, Universidade do Oeste Paulista - Unoeste, Presidente Prudente - SP.

DIAS, G. F. Educação Ambiental: Princípios e Praticas. 9ae ed., São Paulo: Gaia, 2004.

Educação e Gestão Ambiental. 1. a ed. - São Paulo: Gaia, 2006.

ELEUTÉRIO, C. E. Rio vai investir quase R\$ 1 bilhão na gestão do lixo. Eco21. Rio de Janeiro, 181 ed. Disponível em: http://www.eco21.com.br/textos/textos.asp?ID=2606. Acesso em: 22 fev. 2012. 
JARDIM, N.S. Lixo Municipal: manual de gerenciamento integrado. São Paulo: Instituto de Pesquisas Tecnológicas (IPT) e Compromisso Empresarial para Reciclagem (CEMPRE), 1995.

MILARÉ, E. Direito do Ambiente. São Paulo: Revista dos Tribunais, 2000. 678p.

MIRANDA, L.L. O que é Lixo. São Paulo: Brasiliense, 1995.

MOTTA, S. Introdução à Engenharia Ambiental. 4.ำ ed. Rio de Janeiro: Expressão Gráfica, 2010.

PROGRAMA DAS NAÇÕES UNIDAS PARA O MEIO AMBIENTE (PNUMA). Panorama Ambiental Global GEO5. Resumo para formuladores de políticas. Disponível em: http://www.pnuma.org.br/admin/publicacoes/texto/GEO5 RESUMO FORMULADORES P OLITICAS.pdf Acesso em: 05 set. 2013.

VASSALO, C. Criar o futuro. Revista Guia Exame - Sustentabilidade. Editora Abril. Novembro 2011. 